\title{
OPTIMIZATION OF REMANUFACTURING PRODUCTION SCHEDULING CONSIDERING UNCERTAIN FACTORS
}

\author{
Zhang, H. P. \\ North China University of Water Resources and Electric Power, Zhengzhou 450046, China \\ E-Mail: zhanghuaping@ncwu.edu.cn
}

\begin{abstract}
This paper attempts to optimize the remanufacturing production scheduling under randomness and fuzziness. Firstly, the rough set theory and multi-objective approximation ranking algorithm were combined into a quality evaluation method of remanufacturing recycling resources, which eliminates the redundant information in quality evaluation. Then, a remanufacturing production scheduling model was constructed under uncertain conditions, and a hybrid algorithm coupling double fuzzy algorithm, backpropagation (BP) neural network and genetic algorithm was developed to solve the model. The simulation results show that the algorithm achieved good convergence and the obtained solution can minimize the total cost of production scheduling and the processing time. This means the model algorithm can effectively optimize the scheduling of remanufacturing production. The research findings shed new light on the fast quality evaluation of recycled resources and the optimization scheduling of remanufacturing production.

(Received, processed and accepted by the Chinese Representative Office.)
\end{abstract}

Key Words: Uncertain Factors, Remanufacturing, Production Scheduling, Optimization, Simulation

\section{INTRODUCTION}

With the rapid consumption of energy and all kinds of resources in the world and increasing seriousness of environmental pollution, the circular economy based on "resource recovery remanufacturing" has become an important approach to great resource-saving and sustainable development $[1,2]$. Automobile-related field is the most mature remanufacturing industry at present, and its main production process includes resource recycling, material screening, reprocessing, and assembly [3, 4].

In the process of remanufacturing production process and overall scheduling, there are a large number of uncertain factors. Fig. 1 shows relevant uncertain factors, including uncertainties in recovery link, disassembly link, reprocessing link and assembly link [5-8]. Due to different manufacturing objects, different production processes, different production controls and different production schedules, the conventional shop scheduling scheme is not suitable for remanufacturing production processes $[9,10]$.

At present, researchers have done researches on the optimization and simulation of remanufacturing shop scheduling. Some researchers analysed the impact of the quality of the recycled products (abrasion, bending, corrosion, etc.) on the cost, processing efficiency and production scheduling in the remanufacturing process [11-13]. Denizel et al. constructed a classification standard for recycling resources and included the standard to the optimization of remanufacturing production scheduling [14]. Pan and Wang simplified the remanufacturing process into the scheduling of flexible production shop [15]. Rahman et al considered the influence of the disassembly of recycled products on the remanufacturing production scheduling, and proposed the optimal scheduling scheme based on minimizing processing time and cost [16]. Ratnaweera et al. analysed the influence of different parameters of recycled products on the production scheduling of remanufacturing workshop [17]. At the same time, some researchers improved the optimization methods of traditional production scheduling, such as queuing network, wireless radio frequency identification, intelligent 
optimization algorithm, and information sharing method, and optimized the scheduling of remanufacturing workshops while considering the characteristics of remanufacturing [18-20]. However, above methods only take into account single uncertainty factors or focus on independent discussion of uncertainty factors, but less on the effects of the superposition of multiple uncertainties on remanufacturing production decisions and scheduling [21-26]. In addition, there are few reports on the description of uncertain factors, production planning and the centralized decision-making of scheduling in the actual production process of remanufacturing workshops [27].

For the above defects, this study constructs a remanufacturing production scheduling model under uncertain conditions, and proposes a hybrid algorithm which combines double fuzzy algorithm, BP neural network and genetic algorithm to solve the model. The research conclusions can provide a new research idea for the fast quality evaluation of recycled resources and the optimization scheduling of remanufacturing production.

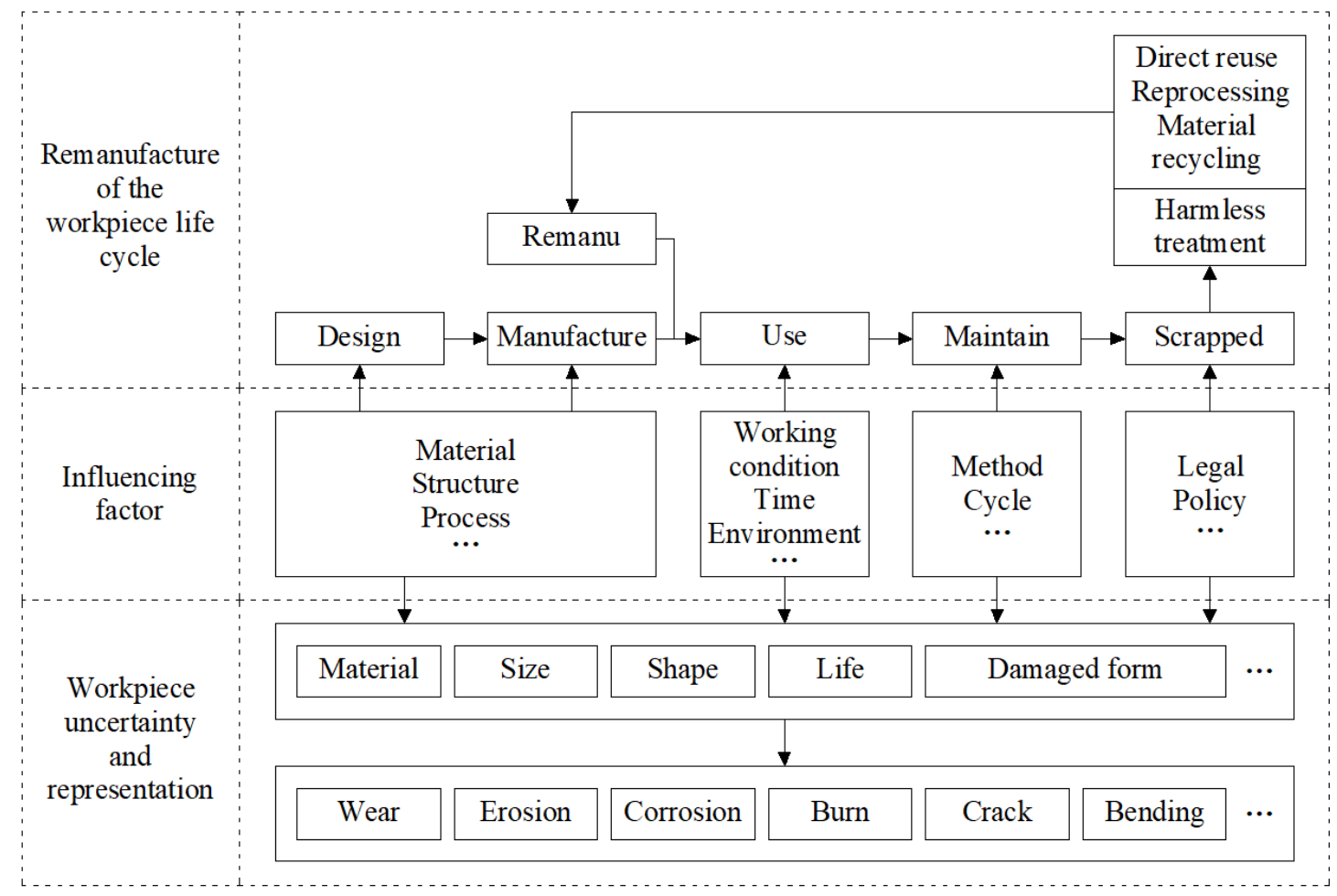

Figure 1: Statistics of uncertain factors in remanufacturing production.

\section{EVALUATION OF THE QUALITY OF REMANUFACTURED WORK PIECES}

The quality of the recycled automobile engines, which are affected by many factors such as the driving life, the maintenance condition, and the external environment of the car, is greatly different. This study takes the parts of the recycled automobile engine as an example to evaluate the quality of recycled products. According to the statistics of relevant data, the crankshaft in the engine is mainly prone to wear, bending, fatigue and burn during operation. The quality of the crankshaft is classified and evaluated with the following parameters as indexes, wear (main shaft $A_{1}$ and connecting neck $A_{2}$ ), main shaft roundness $A_{3}$ and cylindricity $A_{4}$, bending degree $A_{5}$, twist $A_{6}$, shaft spacing $A_{7}$, roughness $A_{8}$, crack $A_{9}$, and burn $\mathrm{A}_{10}$. Table I shows the evaluation and grading standards of the above 10 indexes.

In the table, 10 parameter indexes are divide into 1-4 grades, among which Grade 1 indicates that the loss of crankshaft is small, and the technical requirement can be met after 
proper polishing and cleaning; Grade 2 indicates that there are some minor defects in the crankshaft, which can be used after repair; Grade 3 indicates that there are relatively large defects in the crankshaft, which can be used only after special secondary treatment; and Grade 4 indicates that the crankshaft has been seriously damaged and is directly recycled.

Table I: Classification standard for quality evaluation of engine crankshaft.

\begin{tabular}{|c|c|c|c|c|c|c|c|c|c|c|}
\hline Level & $\mathbf{A}_{\mathbf{1}}$ & $\mathbf{A}_{\mathbf{2}}$ & $\mathbf{A}_{\mathbf{3}}$ & $\mathbf{A}_{\mathbf{4}}$ & $\mathbf{A}_{\mathbf{5}}$ & $\mathbf{A}_{\mathbf{6}}$ & $\mathbf{A}_{\mathbf{7}}$ & $\mathbf{A}_{\mathbf{8}}$ & $\mathbf{A}_{\mathbf{9}}$ & $\mathbf{A}_{\mathbf{1 0}}$ \\
\hline 1 & $0-0.04$ & $0-0.04$ & $0-0.05$ & $0-0.05$ & $0-0.17$ & $0-0.12$ & $0.08-0.26$ & $0.2-0.5$ & no & no \\
\hline 2 & $0.04-0.76$ & $0.04-0.76$ & $0.05-0.09$ & $0.05-0.09$ & $0.17-0.32$ & $0.12-0.22$ & $0.26-0.52$ & $0.5-0.7$ & slight & slight \\
\hline 3 & $0.76-1.51$ & $0.76-1.51$ & $0.09-0.13$ & $0.09-0.13$ & $0.32-0.52$ & $0.22-0.32$ & $0.52-1.02$ & $0.7-0.9$ & medium & medium \\
\hline 4 & $1.51-3.0$ & $1.51-3.0$ & $0.13-0.20$ & $0.13-0.2$ & $0.52-1.2$ & $0.32-0.5$ & $1.02-3.0$ & $0.9-1.0$ & severe & severe \\
\hline
\end{tabular}

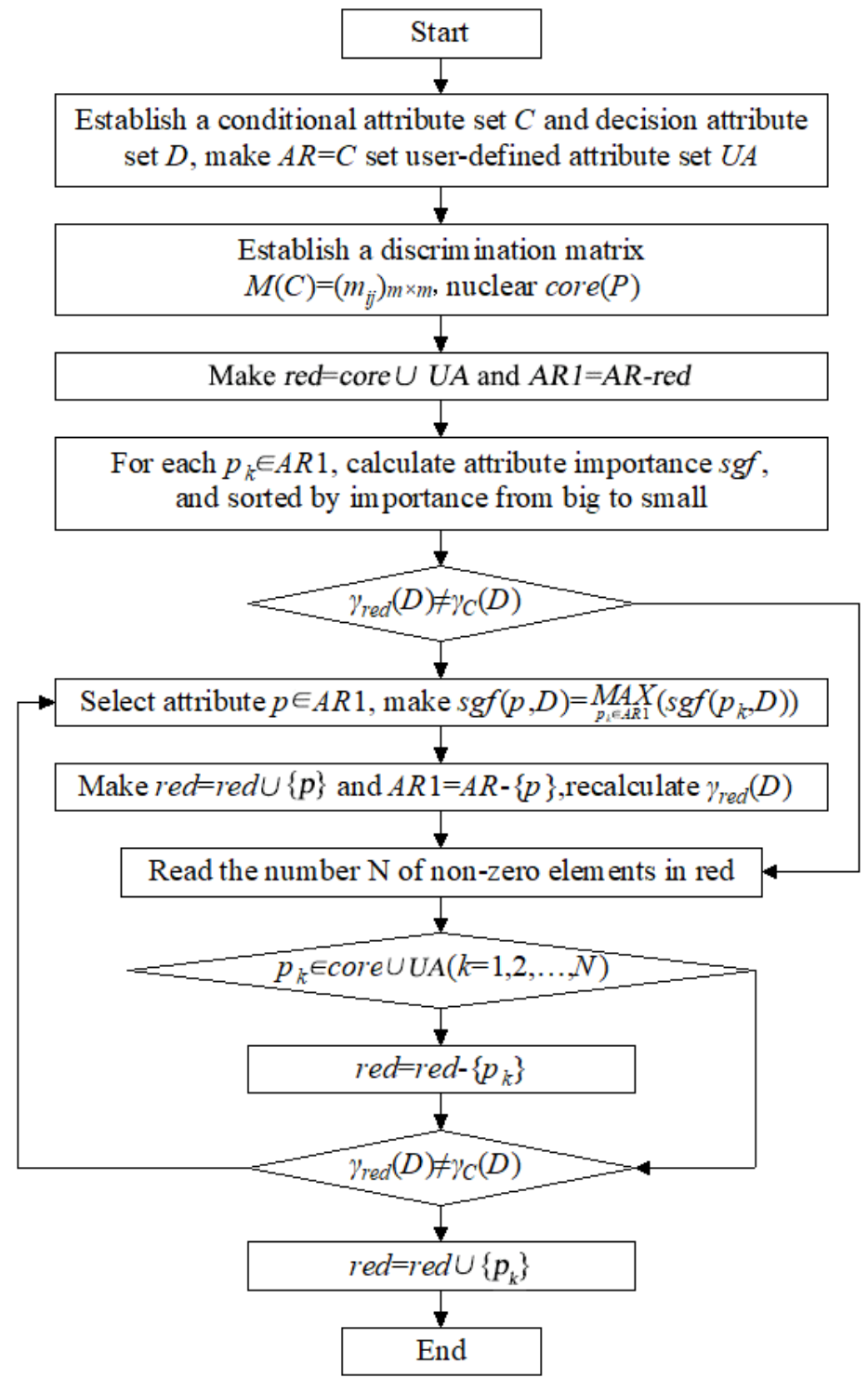

Figure 2: Engine crankshaft quality evaluation flow.

In order to facilitate the real-time evaluation of the recycled crankshaft, the evaluation indexes in Table I are discretized.

$$
\operatorname{sgf}\left(p_{k}, D\right)=\frac{\left|\operatorname{POS}_{C}(D)\right|-\left|\operatorname{POS}_{C-\left\{p_{k}\right\}}(D)\right|}{|U|}
$$


where, $\operatorname{sg} f\left(P_{k}, D\right)$ indicates the importance degree of each evaluation parameter, and the larger the value is, the more important the evaluation parameter is. The weight value of each evaluation parameter is as follows:

$$
w\left(p_{k}\right)=\frac{s g f\left(p_{k}\right)}{\sum_{p_{k} \in C} s g f\left(p_{k}\right)}
$$

The specific process of engine crankshaft quality evaluation is shown in Fig. 2.

\section{REMANUFACTURING PRODUCTION SCHEDULING MODEL AND SOLUTION UNDER UNCERTAIN CONDITIONS}

\subsection{Model description}

The overall process of recycling and remanufacturing of the crankshaft is shown in Fig. 3, which includes engine disassembly, classification according to the crankshaft quality evaluation classification standard, secondary processing and utilization, etc.

According to the above operation flow, the scheduling of automobile engine disassembly and crankshaft reprocessing workshop is summarized as: $m$ sets of machine groups and $n$ types of products to be processed in the workshop, and the following assumptions need to be satisfied in the scheduling optimization process:

a) Each product to be repaired corresponds to one optional equipment set, and after a certain equipment machine is selected in the equipment set, the machine can only repair the product at the same time;

b) The product can only be repaired and reprocessed by the selected machine at the same time;

c) The product can be processed at the initial time, and the time of transportation, pretreatment and waiting in queuing of the product in the workshop is calculated within the entire processing time.

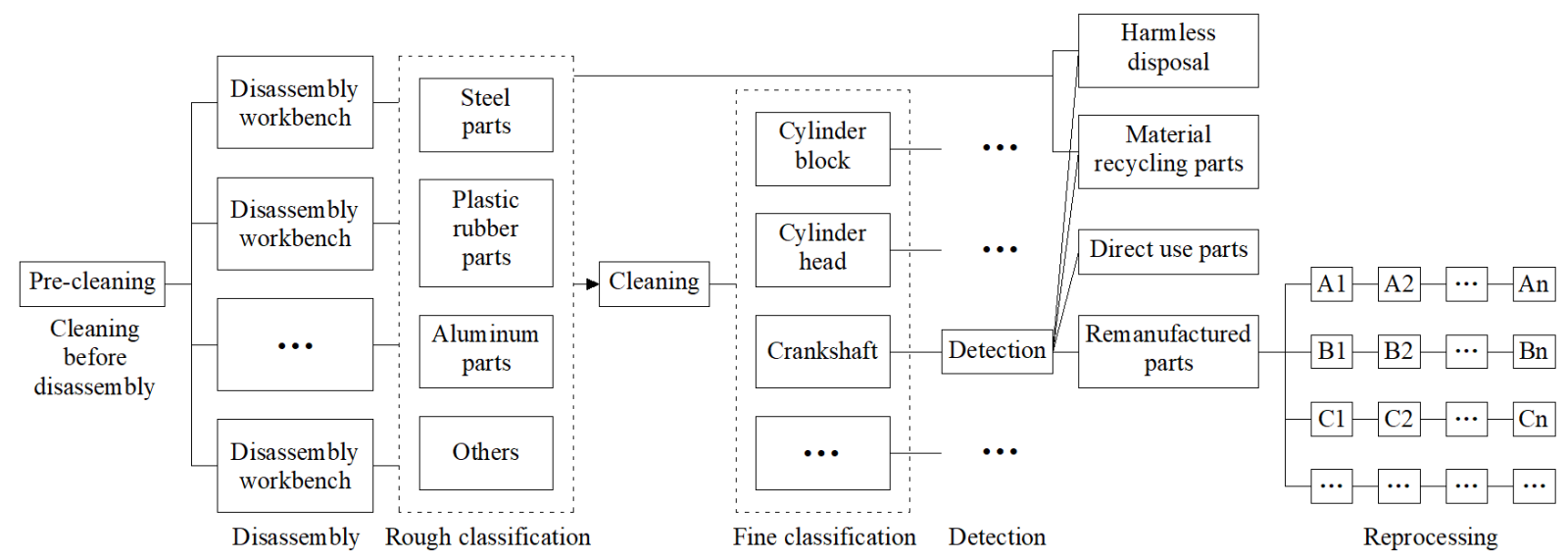

Figure 3: Overall process of recycling and remanufacturing of the crankshaft.

In this study, the dual uncertainty factors such as randomness and fuzziness of shop scheduling in the remanufacturing industry are fully considered in designing the remanufacturing production scheduling model. Under reasonable confidence level, the optimal machine and the optimal processing order are selected for each product. The optimal objective function of the model is as follows:

$$
\min C=\sum_{i=1}^{N} \sum_{j=1}^{N_{i}} \sum_{k=1}^{M_{i j}} M H C_{i k} \cdot R T_{i j k} \cdot \eta_{i j k}
$$




$$
\begin{gathered}
\text { s.t. } \quad E T_{i N_{i}} \leq D D_{i} \\
B T_{i(j+1)}-B T_{i j} \geq R T_{i j k} \\
B T_{i j}-B T_{i^{\prime} j^{\prime}} \geq R T_{i^{\prime} j^{\prime} k}
\end{gathered}
$$

where, $i, j$ and $k$ represents product number, processing procedure number and processing machine number, respectively; $M H C_{i k}$ represents time cost for processing the product; $R T_{i j k}$ is processing time; $E T_{i j}$ represents the processing time of the $i^{\text {th }}$ product on the $j^{\text {th }}$ processing step. Eqs. (4) to (6) are constraints of the objective function.

Double fuzzy variables are introduced to convert the total processing time of the product into triangular discrete fuzzy variables.

$$
R T_{i j k}(\theta)=\left\{\begin{array}{c}
\left(\eta_{1}^{1}, \eta_{1}^{2}, \eta_{1}^{3}\right), \theta=\theta_{1} \\
\left(\eta_{2}^{1}, \eta_{2}^{2}, \eta_{2}^{3}\right), \theta=\theta_{2} \\
\cdots \\
\left(\eta_{r}^{1}, \eta_{r}^{2}, \eta_{r}^{3}\right), \theta=\theta_{r}
\end{array}\right.
$$

where, $\eta_{r}{ }^{l}$ represents optimistic value of the product at the completion time; $\eta_{r}^{2}$ represents maximum probability value of the product at the completion time; $\eta_{r}{ }^{3}$ represents pessimistic value of the product at the completion time. In the actual scheduling optimization, it is necessary to ensure that $\eta_{r}{ }^{3}$ is as small as possible, then the dual fuzzy chance constraint model is:

$$
\left\{\begin{array}{l}
\min \bar{f} \\
\text { s.t.Ch }\{f(x, \xi) \leq \bar{f}\}(\gamma) \geq \delta \\
\quad \operatorname{Ch}\left\{g_{i}(x, \xi) \leq 0\right\}\left(\alpha_{i}\right) \geq \beta_{i}, i=1,2, \ldots, p
\end{array}\right.
$$

where, $\Xi$ is double fuzzy vector. Take Eq. (8) into the original scheduling model, and take the total cost pessimistic value of product production processing scheduling of the entire workshop as the objective function, that's,

$$
\left\{\begin{array}{l}
\min \bar{C} \\
\text { s.t. } C h\{C \leq \bar{C}\}(\gamma) \geq \delta
\end{array}\right.
$$

Under the above conditions, Eqs. (4) to (6) can be converted into:

$$
\begin{gathered}
C r\left\{\theta \in \Theta \mid \operatorname{Cr}\left\{E T_{i N_{i}}-D D_{i} \leq 0\right\} \geq \beta_{i}\right\} \geq \alpha_{i} \\
\operatorname{Cr}\left\{\theta \in \Theta \mid \operatorname{Cr}\left\{R T_{i j k}-B T_{i(j+1)}+B T_{i j} \leq 0\right\} \geq \beta_{i}^{\prime}\right\} \geq \alpha_{i}^{\prime} \\
\operatorname{Cr}\left\{\theta \in \Theta \mid \operatorname{Cr}\left\{R T_{i^{\prime} j^{\prime} k}-B T_{i j}+B T_{i^{\prime} j^{\prime}}\right\} \geq \beta_{i}^{\prime \prime}\right\} \geq \alpha_{i}^{\prime \prime}
\end{gathered}
$$

\subsection{Model solution}

It is very difficult to solve the scheduling model of remanufacturing production under uncertain factors by using theoretical analysis method. In this study, a hybrid algorithm combining double fuzzy algorithm, BP neural network and genetic algorithm is proposed to solve the optimization model proposed in the above section.

Firstly, the original data of the model simulation is generated by using the double fuzzy algorithm, with the specific steps as follows: 
(1) Obtain the upper limit value $\beta$ of the objective function at the maximum confidence level according to Eqs. (10) to (12), and $\theta_{k}$ is $\operatorname{Pos}\left\{\theta_{k}\right\}>\varepsilon$;

(2) For any $r$, there is:

$$
L(r)=\frac{1}{2}\left[\max _{1 \leq k \leq N}\left\{\operatorname{Pos}\left\{\theta_{k}\right\} \mid f\left(\theta_{k}\right) \leq r\right\}+\min _{1 \leq k \leq N}\left\{1-\operatorname{Pos}\left\{\theta_{k}\right\} \mid f\left(\theta_{k}\right)>r\right\}\right]
$$

The extreme value $r$ when $L(r)>\alpha$ is obtained from the above equation, and then the objective function is estimated.

(3) The original data obtained by the double fuzzy algorithm is taken as training samples and brought into the BP neural network algorithm for determining the following functions:

$$
\begin{gathered}
U_{1}(x)=\min \left\{\bar{C} \mid C h\left\{C_{\max } \leq \bar{C}\right\}(\gamma) \geq \delta\right\} \\
U_{i}(x)=C h\left\{E T_{i j}-D D_{i} \leq 0\right\}\left(\alpha_{i}\right) \geq \beta, i=1,2, \ldots, p
\end{gathered}
$$

Genetic algorithm is used to optimize the local optimality and slow convergence of BP neural network algorithm. The initial weight $\mathrm{w}$ is first updated using the improved crossover and mutation operation and then the error function $E_{k}$ is calculated, after which the fitness of each $w$ is calculated by $E_{k}$, and the above steps are repeated until a preset number of iterations is reached.

Based on process code

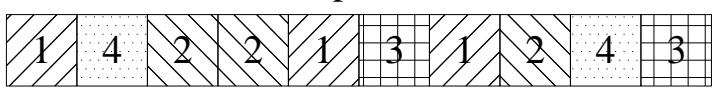

Based on device code

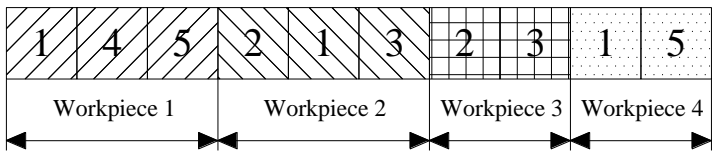

Figure 4: Combined coding form.

After the BP neural network is optimized by genetic algorithm, the optimal network structure and parameters are obtained, the network structure is embedded in the genetic algorithm, and the target output of chromosome is calculated.

Coding: The chromosome of genetic algorithm is coded based on the form of combination coding $(n+m), n$ indicates that there are $n$ kinds of genes in the processing sequence of the product in the whole workshop; $m$ indicates that there are $m$ kinds of product distribution types on the machine. Fig. 4 illustrates a schematic diagram of processing scheduling of four products on five machines.

Initialization: The number of chromosomes, the population, the crossover operator, the genetic operator and the iteration threshold in the genetic algorithm are initialized.

Arrange the calculated output values, and the algorithm terminates when the iteration reaches the set number of times. The hybrid algorithm solution flow of manufacturing scheduling under uncertain conditions is shown in Fig. 5.

\section{SIMULATION EXAMPLE VERIFICATION}

The hybrid algorithm of remanufacturing production scheduling under uncertain conditions proposed in this study is validated, taking 10 engines to be disassembled, with the expected processing scheduling time and lower and upper confidence levels ( $r$ and $\delta$ ) of the internal crankshaft are shown in Fig. 6. 

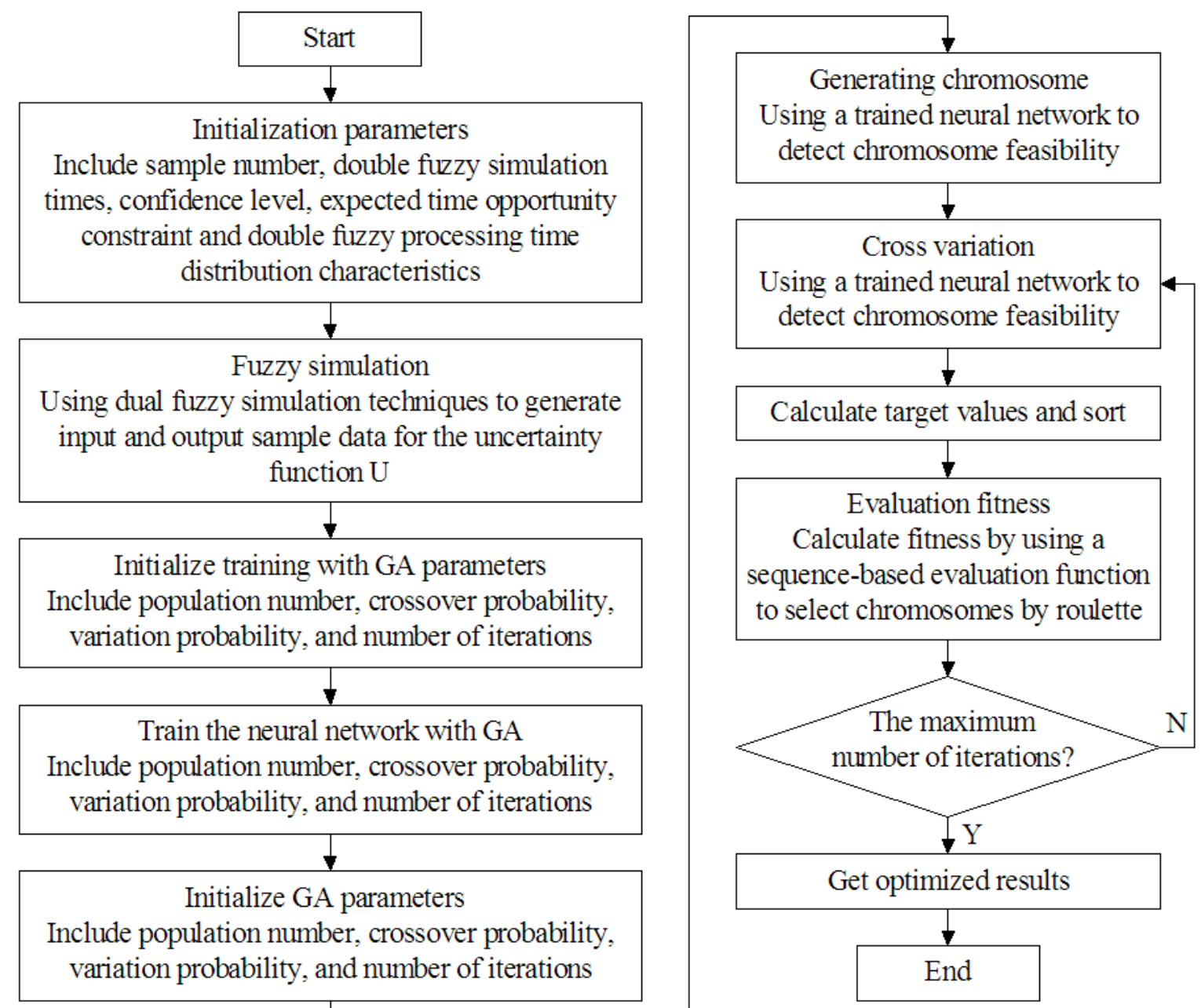

Figure 5: Hybrid algorithm solution flow of remanufacturing production scheduling under uncertain conditions.
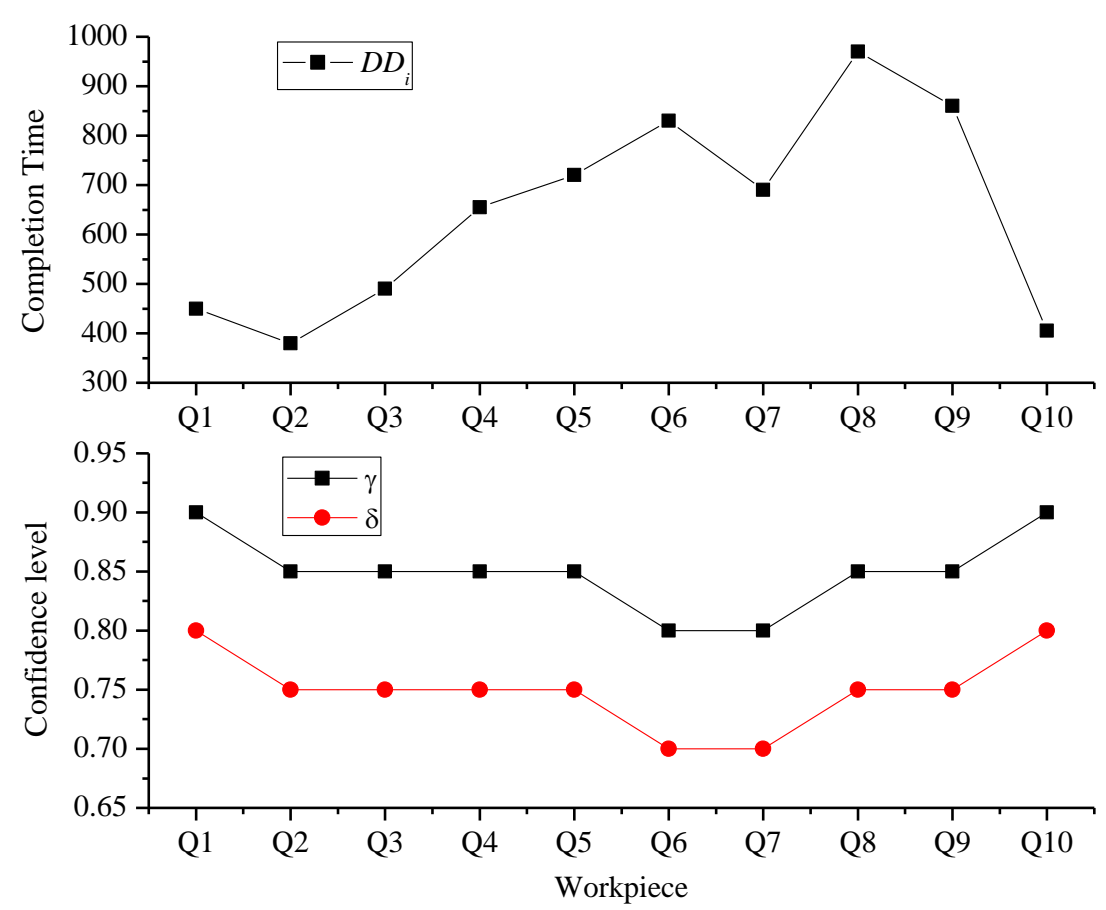

Figure 6: Expected processing time and upper and lower confidence level of engine crankshaft. 
The pre-evaluation results of the 10 engine crankshafts are shown in Table II, where M1-M3 indicate the processing machine, and the crankshaft is divided into a low grade and a high grade according to the evaluation quality in Table I. The processing time corresponding to M1-M3 in the table represents the most optimistic scheduling completion time, the most probable scheduling completion time and the most pessimistic scheduling completion time, respectively.

Table II: Engine crankshaft processing scheduling expected time.

\begin{tabular}{|c|c|c|c|c|c|}
\hline \multirow{2}{*}{ Workpiece } & \multirow{2}{*}{$\begin{array}{c}\text { Quality } \\
\text { classification level }\end{array}$} & \multirow{2}{*}{ Credibility } & \multicolumn{3}{|c|}{ Device } \\
\cline { 3 - 6 } & Low & 0.14 & $(132,140,148)$ & $(136,142,148)$ & $(126,130,134)$ \\
\cline { 2 - 6 } $\mathrm{Q}_{1} \mathrm{Q}_{10}$ & High & 0.82 & $(162,177,192)$ & $(158,168,178)$ & $(164,174,184)$ \\
\hline $\mathrm{Q}_{2} \mathrm{Q}_{3} \mathrm{Q}_{4}$ & Low & 0.12 & $(132,137,142)$ & $(135,140,145)$ & $(134,136,138)$ \\
$\mathrm{Q}_{5} \mathrm{Q}_{8} \mathrm{Q}_{9}$ & High & 0.08 & $(157,164,171)$ & $(158,168,178)$ & $(154,165,176)$ \\
\hline \multirow{2}{*}{$\mathrm{Q}_{6} \mathrm{Q}_{7}$} & Low & 0.90 & $(135,138,141)$ & $(137,142,147)$ & $(130,136,142)$ \\
\cline { 2 - 6 } & High & 0.12 & $(156,164,172)$ & $(155,166,177)$ & $(161,171,181)$ \\
\hline
\end{tabular}

The crossover probability and mutation probability are set to 0.55 and 0.2 respectively, the total number of iterations is 1,000 , and the initial population size is 50 . The complexity $C D$ of production scheduling under uncertain conditions includes:

$$
C D=O\left(T_{s a} S_{i t} \log n+T_{i t} T_{p o p}+G_{i t}(n p o p+n m \log n)\right)
$$

where, $O\left(T_{i t} T_{p o p}\right)$ is computational complexity for BP neural networks; $O\left(T_{s a} S_{i t} \log n\right)$ is the complexity of double fuzzy algorithm and $O($ npop) is the complexity of initialization. The algorithm designed in this study is the set of complexities above, which is mainly related to the double fuzzy algorithm, BP neural network and genetic algorithm.

The algorithm here is used for calculation, and the simulation results are shown in Table III, which shows that the overall pessimistic value of product production processing scheduling tends to increase when the reliability increases gradually. Because there are great differences in the processing order of each product under different confidence levels, when the confidence level is fixed, the solution obtained by using the algorithm in this study can guarantee the minimum total cost and the minimum processing time for the product processing sequence with many uncertain factors.

The convergence curve of the optimal solution is shown in Fig. 7. It can be seen from Fig. 7 that the algorithm presented in this study has very good convergence. When the number of iterations reaches 300 , the convergence state has been reached.

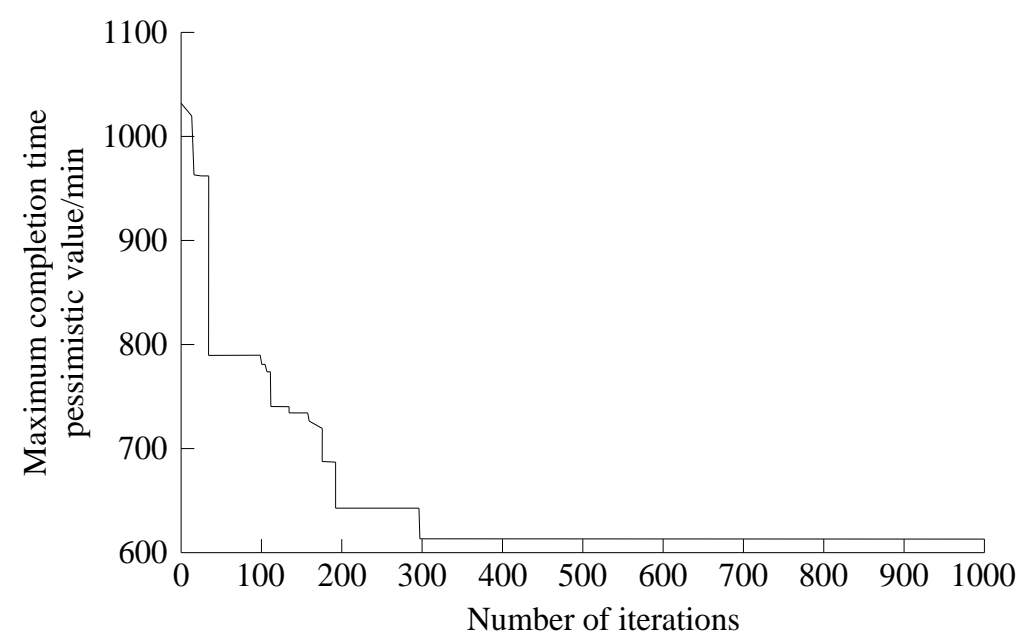

Figure 7: Convergence curve of the optimal solution. 
Table III: Simulation results and verification analysis.

\begin{tabular}{|c|c|c|c|}
\hline \multirow{2}{*}{ Credibility } & \multirow{2}{*}{ Completion cycle $\overline{\boldsymbol{f}} / \mathbf{m i n}$} & \multicolumn{2}{|c|}{ Verification analysis } \\
\cline { 3 - 4 } & & Original opportunity & $\begin{array}{c}\text { Pessimistic value of the } \\
\text { completion cycle/min }\end{array}$ \\
\hline 0.7 & 611.2 & 0.90 & 665.6 \\
\hline 0.8 & 641.8 & 0.86 & 697.3 \\
\hline 0.9 & 656.5 & 0.83 & 715.4 \\
\hline
\end{tabular}

\section{CONCLUSIONS}

In terms of many uncertain factors in the process of remanufacturing production scheduling, this study builds a remanufacturing production scheduling model under uncertain conditions, and proposes a hybrid algorithm combining double fuzzy algorithm, BP neural network and genetic algorithm to solve the model. The conclusions are as follows:

(1) This study establishes a quality evaluation method of remanufacturing recycling resources, which combines rough set theory and multi-objective approximation sorting algorithm, can better eliminate the redundant information in the quality evaluation process, and provides a quick and effective method for quality evaluation of recycled products.

(2) The model takes into account the double uncertainty factors such as randomness and fuzziness of shop scheduling in the remanufacturing industry. Firstly, the double fuzzy algorithm is used to generate the raw data of model simulation, and then is brought into BP neural network algorithm, and the uncertain function of the model is obtained based on the characteristics of BP neural network. In addition, genetic algorithm is used to optimize the local optimality and the slow convergence of BP neural network algorithm.

(3) The simulation results show that the algorithm presented in this study has good convergence and the solution can guarantee the minimum total cost of production scheduling and the minimum processing time. The model algorithm can effectively optimize the scheduling problem of remanufacturing production processing.

\section{ACKNOWLEDGEMENT}

This paper is supported by Decision Research Bidding Project of People's Government of Henan Province (2018B024).

\section{REFERENCES}

[1] Guide, V. D. R. Jr. (2000). Production planning and control for remanufacturing: industry practice and research needs, Journal of Operations Management, Vol. 18, No. 4, 467-483, doi: $10.1016 / \mathrm{s} 0272-6963(00) 00034-6$

[2] Lage, M.; Filho, M. G. (2012). Production planning and control for remanufacturing: literature review and analysis, Production Planning \& Control, Vol. 23, No. 6, 419-435, doi: $10.1080 / 09537287.2011 .561815$

[3] Chaowanapong, J.; Jongwanich, J.; Ijomah, W. (2017). Factors influencing a firm's decision to conduct remanufacturing: evidence from the Thai automotive parts industry, Production Planning \& Control, Vol. 28, No. 14, 1139-1151, doi:10.1080/09537287.2017.1341652

[4] Zhu, Q.; Tian, Y. (2016). Developing a remanufacturing supply chain management system: a case of a successful truck engine remanufacturer in China, Production Planning \& Control, Vol. 27, No. 9, 708-716, doi:10.1080/09537287.2016.1166282

[5] Huang, M.; Yi, P.; Shi, T.; Guo, L. (2018). A modal interval based method for dynamic decision model considering uncertain quality of used products in remanufacturing, Journal of Intelligent Manufacturing, Vol. 29, No. 4, 925-935, doi:10.1007/s10845-015-1151-4 
[6] Ng, M. W.; Waller, S. T. (2012). A dynamic route choice model considering uncertain capacities, Computer-Aided Civil and Infrastructure Engineering, Vol. 27, No. 4, 231-243, doi:10.1111/j.1467-8667.2011.00724.x

[7] Wang, Q. F.; Li, C. B. (2012). Study on the uncertain problem for project-based remanufacturing systems, Advanced Materials Research, Vol. 510, 191-195, doi: 10.4028/ www.scientific.net/amr.510.191

[8] Li, C.; Liu, F.; Cao, H.; Wang, Q. (2009). A stochastic dynamic programming based model for uncertain production planning of re-manufacturing system, International Journal of Production Research, Vol. 47, No. 13, 3657-3668, doi:10.1080/00207540701837029

[9] Petrovic, D.; Duenas, A. (2006). A fuzzy logic based production scheduling/rescheduling in the presence of uncertain disruptions, Fuzzy Sets and Systems, Vol. 157, No. 16, 2273-2285, doi:10.1016/j.fss.2006.04.009

[10] Du, J.; Li, Q.; Qiao, F.; Yu, L. (2018). Estimation of vehicle emission on mainline freeway under isolated and integrated ramp metering strategies, Environmental Engineering \& Management Journal, Vol. 17, No. 5, 1237-1248

[11] Gong, D.; Liu, S.; Tang, M.; Ren, L.; Liu, J.; Liu, X. (2018). Revenue sharing or profit sharing? An internet production perspective, Advances in Production Engineering \& Management, Vol. 13, No. 1, 81-92, doi:10.14743/apem2018.1.275

[12] Ling, S. H.; Iu, H. H. C.; Leung, F. H. F.; Chan, K. Y. (2008). Improved hybrid particle swarm optimized wavelet neural network for modeling the development of fluid dispensing for electronic packaging, IEEE Transactions on Industrial Electronics, Vol. 55, No. 9, 3447-3460, doi:10.1109/tie.2008.922599

[13] Coelho, L. dos S.; Herrera, B. M. (2007). Fuzzy identification based on a chaotic particle swarm optimization approach applied to a nonlinear Yo-yo motion system, IEEE Transactions on Industrial Electronics, Vol. 54, No. 6, 3234-3245, doi:10.1109/tie.2007.896500

[14] Denizel, M.; Ferguson, M.; Souza, G. C. (2010). Multiperiod remanufacturing planning with uncertain quality of inputs, IEEE Transactions on Engineering Management, Vol. 57, No. 3, $394-$ 404, doi:10.1109/TEM.2009.2024506

[15] Pan, Q.-K.; Wang, L. (2008). No-idle permutation flow shop scheduling based on a hybrid discrete particle swarm optimization algorithm, International Journal of Advanced Manufacturing Technology, Vol. 39, No. 7-8, 796-807, doi:10.1007/s00170-007-1252-0

[16] Rahman, M. A.; Anwar, S.; Izadian, A. (2016). Electrochemical model parameter identification of a lithium-ion battery using particle swarm optimization method, Journal of Power Sources, Vol. 307, 86-97, doi:10.1016/j.jpowsour.2015.12.083

[17] Ratnaweera, A.; Halgamuge, S. K.; Watson, H. C. (2004). Self-organizing hierarchical particle swarm optimizer with time-varying acceleration coefficients, IEEE Transactions on Evolutionary Computation, Vol. 8, No. 3, 240-255, doi:10.1109/tevc.2004.826071

[18] Liu, M.; Zhang, X.; Liu, C.; Zhang, M.; Ge, M. (2014). Optimization method of remanufacturing reprocessing shop scheduling under uncertain conditions, Journal of Mechanical Engineering, Vol. 50, No. 10, 206-212, doi:10.3901/jme.2014.10.206

[19] An, Y.-W.; Yan, H.-S. (2013). Solution strategy of integrated optimization of production planning and scheduling in a flexible job-shop, Acta Automatica Sinica, Vol. 39, No. 9, 14761491, doi:10.3724/sp.j.1004.2013.01476

[20] Vand, A. Z.; Mirzaei, M.; Ahmadi, M. H.; Lorenzini, G.; Kumar, R.; Jilte, R. (2018). Technical and economical optimization of CHP systems by using gas turbine and energy recovery system, Mathematical Modelling of Engineering Problems, Vol. 5, No. 4, 286-292, doi:10.18280/mmep.050403

[21] Andrew-Munot, M.; Ibrahim, R. N. (2013). Development and analysis of mathematical and simulation models of decision-making tools for remanufacturing, Production Planning \& Control, Vol. 24, No. 12, 1081-1100, doi:10.1080/09537287.2012.654667

[22] Tang, M.; Qi, Y.; Zhang, M. (2017). Impact of product modularity on mass customization capability: An exploratory study of contextual factors, International Journal of Information Technology \& Decision Making, Vol. 16, No. 4, 939-959, doi:10.1142/S0219622017410012 
[23] Rubio, S.; Corominas, A. (2008). Optimal manufacturing-remanufacturing policies in a lean production environment, Computers \& Industrial Engineering, Vol. 55, No. 1, 234-242, doi:10.1016/j.cie.2007.12.009

[24] Aras, N.; Verter, V.; Boyaci, T. (2006). Coordination and priority decisions in hybrid manufacturing/remanufacturing systems, Production and Operations Management, Vol. 15, No. 4, 528-543, doi:10.1111/j.1937-5956.2006.tb00161.x

[25] Wang, J.; Zhao, J.; Wang, X. (2011). Optimum policy in hybrid manufacturing/remanufacturing system, Computers \& Industrial Engineering, Vol. 60, No. 3, 411-419, doi:10.1016/ j.cie.2010.05.002

[26] Dauzère-Pérès, S.; Lasserre, J.-B. (2002). On the importance of sequencing decisions in production planning and scheduling, International Transactions in Operational Research, Vol. 9, No. 6, 779-793, doi:10.1111/1475-3995.00388

[27] Xiao, Y. Q.; Wang, L.; Li, Q. (2014). Research on the integration model of process planning and job-shop scheduling, Applied Mechanics and Materials, Vol. 513-517, 1605-1608, doi:10.4028/www.scientific.net/amm.513-517.1605 